\title{
MANIFESTAÇÕES ANTIPOSITIVISTAS NO PENSAMENTO JURÍDICO DA UNIVERSIDADE DE COIMBRA NO SÉCULO XX: UMA RECONSTITUIÇÃO HISTÓRICA DIALOGADA COM PAULO MERÊA, CABRAL DE MONCADA E CASTANHEIRA NEVES.
}

\section{RESUMO}

Aline de Almeida Silva Sousa ${ }^{1}$

O presente estudo convoca grandes vozes do pensamento jurídico da Faculdade de Direito da Universidade de Coimbra no séc. XX, na medida em que as três contribuíram de forma paradigmática para a superação da mentalidade juspositivista cientificista naquele contexto. $\mathrm{O}$ primeiro condutor, Paulo Merêa, é lembrado como a primeira reação antipositivista e antitotalitária em defesa dos direitos subjetivos. Já a segunda voz, a de Cabral Moncada, é lembrada pela retomada da cátedra de Filosofia do Direito. Por fim, convoca-se também Castanheira Neves, por sua grande contribuição para o pensamento jusfilosófico contemporâneo.

Palavras-chave: Pós-positivismo jurídico; Filosofia do Direito; Universidade de Coimbra; Século XX; Justiça.

\section{ANTIPOSITIVISTS MANIFESTATIONS IN THE LEGAL THINKING OF THE UNIVERSITY OF COIMBRA IN THE 20th CENTURY: AN HISTORICAL RECONSTITUTION DIALOGUED WITH PAULO MERÊA, CABRAL DE MONCADA AND CASTANHEIRA NEVES.}

\begin{abstract}
The present study summons great voices of the legal thought of the Faculty of Law of the University of Coimbra in the 20th century, as the three names have contributed in a paradigmatic way to overcome the scientificist juspositivistic mentality. The first name, Paulo Merêa, is remembered as the first antipositivist and antitotalitarian reaction in defense of the subjective rights. The second voice, Cabral de Moncada, is remembered for the reopening of the studies about Philosophy of Law. Finally, Castanheira Neves is also summoned for his magnificent contribution to jusphilosophical contemporary thinking.
\end{abstract}

Keywords: Legal post-positivism; Philosophy of Law; University of Coimbra; 20th Century; Justice.

\section{INTRODUÇÃO}

O presente estudo consiste numa jornada pelos últimos cem anos de história (na verdade, um pouco mais) do pensamento jusfilosófico da Faculdade de Direito da Universidade de Coimbra. Importa, na verdade, pôr em voga as incontornáveis vozes críticas

*Doutoranda e Mestre em Ciências Jurídico-Filosóficas pela Universidade de Coimbra (Portugal). alinesousa.0909@gmail.com

Revista Brasileira de História do Direito | e-ISSN: 2526-009X | Encontro Virtual | v. 7 | n. 2 |

p. $60-80$ | Jul/Dez. 2021. 
e superadoras do positivismo jurídico no séc. $\mathrm{XX}$, tendo em vista as pretensões cientificistas organicistas para a eliminação das reflexões metafísicas e axiológicas, o que não deixavam de implicar numa eliminação do pensamento jusfilosófico. Desta feita, os nossos condutores guias selecionados tiveram importantes papéis para a superação desta mentalidade, e o presente trabalho propõe elucidar tais contributos.

O nosso primeiro guia, Paulo Merêa, embora hoje seja conhecido como um dos maiores nomes de Jurídico-Históricas em Portugal (TEIXEIRA, 1983, p. 160), quando afrontou a abordagem organicista da sociedade, na sua orientação pela ultra-estatização do direito pela eliminação dos direitos individuais e consequente hipertrofia dos deveres sociais (PAULO MERÊA, 1973, p. 285-324), ainda era um estudante de graduação. Importa reconhecer que a sua voz insurgente é mencionada como uma distinta manifestação antipositivista na história de Coimbra, na sua tarefa de recuperar o valor do indivíduo por si mesmo, e não somente em torno dos contributos para o todo orgânico-social. (TEXEIRA, 1983, p. 113).

Já o nosso segundo condutor, Cabral de Moncada, quando felizmente enveredouse pela Filosofia do Direito, foi responsável pela tarefa importante de retomar os seus estudos na Faculdade de Direito da Universidade de Coimbra, assumindo a posição de uma verdadeira voz restauradora das reflexões filosóficas sobre o direito. (CABRAL DE MONCADA, 19371938, p. 163-167).

Finalmente, o nosso último jusfilósofo, Castanheira Neves, ainda permanece em voga no pensamento jurídico-filosófico e metodológico-jurídico contemporâneo. Importa, portanto, pincelar a sua elaboração do «direito como validade», que não é orientada por um ideal supracultural de justiça, e que também não se confunde com um mero instrumento regulador da sociedade para a realização de fins externos ao direito, como nos termos dos sociologismos (CASTANHEIRA NEVES, 2011, p. 297-299). Contudo, também não se trata de uma mera confusão entre direito e moral, mas de uma separação, que permite autonomizar a materialidade do direito. (AROSO LINHARES, 2016, p. 437).

Ainda, cabe mencionar que o presente estudo foi realizado através da revisão bibliográfica dos materiais e outros documentos originais da biblioteca da Faculdade de Direito da Universidade de Coimbra, bem como da sua sala de revistas que guarda todos os periódicos já publicados pela FDUC. 


\section{CONTEXTUALIZAÇÃO GERAL DO PENSAMENTO JUSFILOSÓFICO DE COIMBRA DE 1869 ATÉ 1911.}

De modo generalizado, porém não homogêneo, o pensamento jurídico português, do final do século XIX até as primeiras décadas do séc. XX, é marcado pela irradiação do positivismo de caráter sociológico e organicista, bem como pelos cientismos, naturalismos, evolucionismos e utilitarismos em ascensão na mentalidade científica da época. Manifestavase uma firme crença na razão humana identificada à razão científica, haja vista que o verdadeiro conhecimento deveria ser submisso aos métodos positivos das ciências naturais, a partir dos quais se intentava explicar de modo unitário toda a realidade. Neste sentido, vê-se uma tendência para afastamento das reflexões metafísicas, éticas e filosóficas de modo geral. (SOUSA, 2005, p. 13).

Cabral de Moncada (2003, p. 115-117) elucida que a falta de hábito para reflexões filosóficas juntamente como o contexto cultural e político do país contribuíram para que, desde 1880, o modelo de pensamento predominante em Portugal fosse o naturalismo positivista de base materialista. A partir daquele mesmo ano, as teses de filosofia do direito defendidas em Coimbra mostraram, em sua grande maioria, o predomínio do sociologismo e do naturalismo positivista. Deste modo, dispensou-se cada vez em maiores graus os debates sobre direito natural, numa aproximação do positivismo jurídico voltado para o cientificismo, em termos sociológicos, históricos, biológicos, causais e entre outros. Por conseguinte, concebia-se como o único direito existente aquele positivado na sua formação histórica e legislativa.

A partir de então, quase nada mais se escreveu sobre direito natural. Entretanto, o ensino da filosofia arrasta-se para o séc. XX, embora decadente, mantido pela força conservadora da tradição, mas que já não é levado a sério, com uma importância cada vez mais mitigada (CABRAL DE MONCADA, 2003, p. 117). Entretanto, o culminar do seu fim ocorre com a supressão da cadeira de Filosofia do Direito em 1911, um ano após a morte do último professor, o Doutor Avelino Calisto. A Reforma de 24 de dezembro de 1901 já havia alterado o nome da disciplina para Sociologia Geral e Filosofia do Direito e, sob influência das mesmas linhas de pensamento, o ensino da filosofia do direito é definitivamente suprimido em 1911 (TEIXEIRA, 2003, p. 7 e 8). Por esta razão, a filosofia do direito nem 
aparece nos primeiros anos do Boletim da Faculdade de Direito da Universidade de Coimbra e a sua abertura só acontece timidamente anos mais tarde (REIS MARQUES; GAUDÊNCIO; LINHARES, 2015, p. 6).

De fato, assinalou-se uma clara mentalidade antifilosófica no cerne da educação jurídica portuguesa, institucionalizando a partir da reforma já referida a perspectiva sociológica do direito sob influência comteana, spenceriana e entre outras. Direcionou-se, deste modo, os estudos para a análise da sociedade como um fenômeno, a fim de elucidar o que há de fundamental e geral para o "organismo" jurídico, a partir do exame da sua elaboração histórica (CABRAL DE MONCADA, 2003, p. 118), numa abordagem positivista epistemológica. Esta linha de pensamento triunfou quase sem subversões, exceto pela voz insurgente do próximo capítulo.

Cabral de Moncada (2003, p. 175-177) assinala que a rapidez e profundidade da expansão do positivismo naturalista em Portugal se deve além do fato de ter sido um fenômeno geral do pensamento europeu, bem como em razão dos grandes triunfos das ciências naturais a partir do seu método experimental e, inclusive, pelo descrédito do idealismo alemão. Esta rápida expansão é revestida de um caráter particular, não explicada por nenhuma das razões ora expostas. Na verdade, além do simplismo da visão de mundo facilmente assimilável, o positivismo foi produto de uma tentativa de oposição ao tradicionalismo escolástico jusnaturalista. Isto, de certo modo, já havia ocorrido no séc. XVIII com a introdução da Filosofia Moderna, que convertia o problema filosófico num problema cultural e pedagógico. Neste sentido, o juspositivismo sociológico que vigorava naquele período se tratava menos de um pensamento filosófico e mais de uma aplicação de métodos científicos em temas filosóficos, viabilizando uma facilitada assimilação popular. Por conseguinte, a difusão desse pensamento contribuiu para o quase desaparecimento da filosofia do direito em Portugal.

\section{O JOVEM MANUEL PAULO MERÊA: A VOZ INSURGENTE.}


A voz de Manuel Paulo Merêa (1889-1977) ${ }^{2}$ é referida como a primeira a reagir de forma negativa diante das tendências positivistas ora expostas no capítulo anterior (TEIXEIRA, 1983, p. 113). Embora ainda fosse apenas estudante da Faculdade de Direito da Universidade de Coimbra, em 1910, na conferência chamada "Idealismo e Direito", Paulo Mêrea se fez notável por golpear de forma incisiva as tendências positivistas cientificistas, especialmente contra as de influência da Escola Sociológica de Duguit (CABRAL DE MONCADA, 1960, p. 3). A conferência por si mesma foi considerada uma forma implícita de refutação ao então reitor da Universidade, Manuel d'Arriaga, tendo em vista o seu constante enaltecimento ao cientismo. (CABRAL DE MONCADA, 2003, p. 199).

A obra "Idealismo e Direito" é fruto dessa destacada e singular reflexão ante a dominante mentalidade positivista sociológica do séc. XIX, através da qual Mêrea demonstra a sua irresignação e o seu propósito de expiar as tendências naturalistas, em torno de um resgate idealista. $\mathrm{Na}$ verdade, trata-se de uma reação contra as tendências filosóficas excludentes umas das outras. (PAULO MÊREA, 1973, p. 287-288).

Com efeito, Paulo Merêa (1973, p. 288-294) atesta primeiramente que o pensamento e a realidade não são entidades apartadas, mas resultado de uma cisão que ocorre através da experiência, que não é nem somente subjetiva/psicológica ou objetiva/física. Em seguimento, o que mais suscitou a reação idealista foi a identificação das preocupações nãoneutras, materialistas, por detrás do rótulo da cientificidade. Mêrea elucida que qualquer pensamento filosófico, mesmo o positivista, só alcança tal patamar se conseguir englobar os dados particulares numa coerência unitária metódica. Reconhece-se, portanto, que fatos isolados não podem constituir um modelo de pensamento, mas uma restrita filosofia puramente especulativa também não. Nestes termos, o nosso condutor defende o reconhecimento da necessidade de relacionar diferentes modelos de pensamento para a análise dos fenômenos observados, haja vista a insuficiência interpretativa do método experimental das ciências naturais. Trata-se de uma abordagem neoidealista e pluralista, que conta com diversos métodos para a formulação do conhecimento, rejeitando a pretensa pura objetividade dos sociologismos desse período.

\footnotetext{
${ }^{2}$ Trata-se do mais importante historiador português do séc. XX. Autor de uma vasta obra sobre direito medieval, português, peninsular, de ideias políticas e entre outros assuntos. Formado em Direito pela Universidade de Coimbra em 1912, tornou-se professor assistente logo no ano seguinte. Foi professor também na Universidade de Lisboa. (TEIXEIRA, 1983, p. 160.).
} 
Já no capítulo segundo intitulado "Duguit e o direito subjetivo", Merêa tece críticas sobre a implicações de Duguit na sua rejeição da liberdade moral e, por conseguinte, da própria ideia de direito subjetivo, resultando numa hipertrofia dos deveres. Sob influência de Comte, Duguit rejeita as noções metafísicas dos direitos do homem (naturais, morais, inalienáveis e imprescritíveis nos termos iluministas) para considerar exclusivamente os direitos impostos pela sociedade, que se identificam com «o direito de cumprir com deveres». (PAULO MÊREA, 1973, p. 299-300). Há, portanto, uma verdadeira negação dos direitos do indivíduo em proveito do poder social estatal.

Numa crítica às tendências ultra-estatistas, Mêrea ressalta que a própria ideia de poder público é uma abstração de cunho metafísico. O Estado, mesmo na construção de Duguit, não pode impor de maneira absoluta a sua vontade pelo fato desta não ser superior às vontades individuais, mas obriga-as apenas à promover solidariedade social. Nestes termos, a fim de evitar o totalitarismo estatal, Duguit busca no sistema dogmático as soluções para esse problema, contudo, esbarra-se nos mesmos resultados de um totalitarismo que observa o Estado como distribuidor de direitos, pois ambos os modelos não disponibilizam garantias inerentes aos indivíduos. Nestes termos, a irresignação de Merêa diante da supressão de direitos individuais não resta preocupada somente com o indivíduo, mas o próprio interesse da coletividade e do progresso social, pois a liberdade não existe sem a personalidade. (PAULO MÊREA, 1973, p. 303-305).

A partir das invocações de Ihering, numa tentativa de equilibrar a racionalidade jurídica com os interesses sociais, ressalta o nosso condutor que os direitos são resultados das conquistas obtidas através da luta e que, diante de todo direito, presume-se a necessidade da sua manutenção. Contudo, não se trata de conceber direitos meramente pela força, mas de ponderar que a luta individual, quando se manifesta como um elemento da própria civilização na sua convocação da liberdade, da ordem e do progresso, é assimilada pela sociedade e pelo direito paulatinamente no seu confronto com o Estado. (PAULO MÊREA, 1973, p. 305-306).

No entanto, não se trata de conceber os direitos subjetivos como entidades metafísicas autoevidentes nos termos iluministas, mas no seu reconhecimento através das relações entre a vontade individual e os efeitos sociais mediadas pelo espírito. Efeitos que devem corresponder aos termos esperados pela vontade geral, a ser consagrada institucionalmente. Mêrea elucida que é neste sentido que verdadeiramente se remonta ao 
positivismo, na medida em que a realidade é concebida para além dos entes externos, pois também necessita das inevitáveis abstrações e sentimentos do espírito. É no sentimento que reside a principal fonte psicológica do direito, capaz de mobilizar resistência diante da injustiça através da luta individual. Portanto, limitar-se a dizer que o direito subjetivo não existe e não pertence ao indivíduo seria o mesmo que promover a apatia existencial. (PAULO MÊREA, 1973, p. 308-311).

Importa ainda reforçar que tais manifestações críticas, apesar de brilhantes, foram feitas por Mêrea quando ainda era estudante (TEIXEIRA, 1983, p. 113). Ele foi descrito por Figueiredo Marcos (2014, p. 449) como um verdadeiro «sábio» da Faculdade de Direito da Universidade de Coimbra, consagrando toda a sua estima na História do Direito, inclusive na História do Direito português. Por essa razão, a Faculdade de Letras da Universidade de Coimbra em 1948 concedeu-lhe Doutoramento Honoris Causa, haja vista ter reerguido a cadeira de História do Direito da FDUC. Ademais, não se pode ignorar as suas contribuições ao Código Civil Português de 1966; as suas participações em agremiações científicas, tanto nacionais como estrangeiras; e muitos outros prêmios e reconhecimento pelas suas contribuições inestimáveis. (FIGUEREDO MARCOS, 2014, p. 456-459).

\section{CABRAL DE MONCADA COMO A VOZ RESTAURADORA DA FILOSOFÍA DO DIREITO NA UNIVERSIDADE DE COIMBRA NO SÉC. XX.}

A obra construída pelo pensamento de Luís Cabral de Moncada (1888-11974) ${ }^{3}$ é polivalente na medida em que perpassa por diversas áreas do conhecimento jurídico. Muitos reconhecem a conjugação dos aspectos de historiador e de filosofo em seus escritos. De fato, é possível observar ao longo de sua obra uma clara transição dos estudos jurídico-históricos com aspectos civilistas para os estudos históricos sobre o pensamento jurídico, embora desde sempre imbuído de preocupação com as ideias fundamentais sobre o direito. Cabral de Moncada passa também pela filosofia política, para finalmente concentrar-se nos estudos filosóficos sobre o direito. (REIS MAQUES; GAUDÊNCIO; LINHARES, 2015, p. 7-18).

Importa mencionar o Decreto n. ${ }^{\circ} 16: 044$ de 13 de outubro de 1928, no seu art. $4^{\circ}$, através do qual a Faculdade de Direito da Universidade de Coimbra em 1936 decidiu por criar

\footnotetext{
3 Luís Cabral de Moncada, licenciado e doutorado pela Faculdade de Direito da Universidade de Coimbra; catedrático desde 1924, na Secção de Ciências Histórico-Jurídicas; jubilou-se em 1958, e faleceu em Coimbra no ano de 1974. (SOUSA, 2005, p. 43).
} 
no quinto ano do curso de direito a cadeira de Filosofia do Direito pela regência de Cabral de Moncada. O objetivo do curso foi, primordialmente, o de problematizar o direito a partir dos problemas da filosofia moderna. (CABRAL DE MONCADA, 1937-1938, p. 163-167). Esse decreto representa um reconhecimento de que filosofar é uma forma de existir, como diriam muitos existencialistas. Isto porque, para poder se negar a filosofia, é preciso ainda fazer filosofia, ou seja, identificar um problema/pergunta para se formular uma resposta, ainda que não seja uma resposta final, como numa teia de Penélope hegeliana. Logo, a eliminação da filosofia como problema, para ter algum êxito, teria de recair na amputação do espírito humano (CABRAL DE MONCADA, 1966, p. 9-11).

É importante sublinhar desde o início, pegando emprestado as percepções de Castanheira Neves (2008, p. 542) quando afirma que a Filosofia do Direito e do Estado de Cabral de Moncada é, na verdade, uma filosofia temática, ou seja, trata-se de uma reflexão filosófica sobre o Estado e sobre o Direito. Não é, portanto, uma filosofia do direito stricto $s e n s u$, pensada em uma perspectiva unitária de inteligibilidade, mas de uma reflexão que parte de problemas gerais da filosofia aplicados ao direito. Considerando tal fato, importa alertar que não se pretende esgotar todos os problemas invocados por Moncada.

Logo, o primeiro problema a ser investigado é o do conhecer em geral, ou seja, «o problema da gnosiologia», considerando que as ciências do Direito e do Estado (ciências do espírito) têm no polo subjetivo a priori uma parte relevante na constituição do objeto e, por conseguinte, da própria realidade (CABRAL DE MONCADA, 1966, p. 27-31), o que implica num claro distanciamento crítico das pretensões meramente descritivas e pretensamente neutras de um objeto totalmente exterior, como ocorre na abordagem meramente epistemológico-descritiva do positivismo. Logo, o problema em causa é o de compreender de que forma o sujeito atua no processo de conhecimento do direito, enquanto forma de conhecimento teorética e discursiva. (CABRAL DE MONCADA, 2004, p. 46-47).

A resposta para este questionamento implica necessariamente o conceito de direito. Nesse sentido, para Moncada, em sua abordagem neokantiana, a primeira ideia que se oferece quando nos debruçamos sobre o conceito de direito é a de «dever-ser». Isto porque partimos das intenções prático-axiológicas, dos valores e das preferências que nos apresentam na consciência intuitivamente, e não dos elementos empíricos concebidos no mundo através das metodologias das ciências naturais. O dever-ser exprime-se através do valor, como um 
fenômeno primário concreto na consciência individual, bem como através da «norma», compreendida como uma construção generalizante, fruto das relações intersubjetivas entre consciências em uma comunidade. (CABRAL DE MONCADA, 2004, p. 49-53).

Neste sentido, o dever-ser, os valores e as normas implicam necessariamente a «liberdade», porquanto o direito só existe para seres livres ou supostamente livres, o que leva a reconhecer que, como todas as normas, o direito só pode ser obedecido se também puder ser descumprido. Um sujeito livre é um sujeito ativo, capaz de se autodeterminar-se, o que se traduz na «personalidade». Logo, não é possível pensar a liberdade sem pensar na personalidade, considerando que a primeira consiste num poder do sujeito, e a segunda implica este próprio sujeito como centro deste mesmo poder, ou seja, a liberdade não existe fora da pessoa e a pessoa não existe sem liberdade. Por conseguinte, a própria ideia de pessoa como ser livre, só pode ser com os outros, com outras personalidades, o que nos reconduz à ideia de alteridade. Trata-se de uma convivência colaborativa e plural entre múltiplas individualidades com diferentes fins, em uma dinâmica socializadora e integradora. (CABRAL DE MONCADA, 2004, p. 55-59). Vê-se, novamente, um radical distanciamento do positivismo sociológico, ainda mais na sua abordagem descritivo-sociológica, que mitigava a liberdade em benefício do todo social, numa hipertrofia dos deveres, o que desconsidera a própria condição de pessoa.

O direito, portanto, é pensado em um nível de convivência de fins, que se condicionam e se implicam mutuamente. Tal conclusão reclama ainda as ideias de «ordem»e «justiça». A ideia formal de ordem é exigida a partir da alteridade, tendo em vista o ajustamento das relações de convivência. A justiça, em seu sentido formal, portanto, consiste numa certa ordem, e quando conta com seus elementos essenciais, pode ser vista como uma «ordem perfeita» (CABRAL DE MONCADA, 2004, p. 60-61). Trata-se de uma ordem fundada no pensamento de "respeitar o fim de cada um e o fim universal de todos, para que [...], possam ser e permanecer aquilo que por essência são, centros livres de atos, e para que reine uma certa ordem no convívio entre eles.” (CABRAL DE MONCADA, 2004, p. 62). Logo, essa clara referência kantiana, numa orientação por uma ideia de justiça como ordem perfeita também demonstra um evidente retorno à metafísica, no abandono dos puros sociologismos descritivos.

No problema gnosiológico, a atividade interpretativa também é considerada, porquanto não há como pensar sem antes interpretar. Trata-se de um compreender 
objetivando, no sentido de apreender aquilo que já está em parte em nós e na coisa, ou seja, uma interpenetração do sujeito no objeto. Deste modo, nenhuma lei é suficientemente clara a ponto de preterir a interpretação, porquanto nem existiriam como objetos do nosso pensamento. Interpretar é o próprio modo de dar existência à lei diante do homem. (CABRAL DE MONCADA, 2004, p. 73).

Desta feita, importa ressaltar a nuance prática inserida na interpretação, na medida em que a aplicação do direito pelo jurista vem vinculada à própria existência do homem, numa realização prática e normativa, distanciando-se do silogismo lógico e da concepção meramente aplicadora da atividade judicial. Entretanto o poder criador do juiz é revelado apenas no âmbito da integração das lacunas, no qual o juiz recorre de forma mais larga à compreensão do global do sistema jurídico (CABRAL DE MONCADA, 1966, p. 77-81), numa clara influência da Jurisprudência dos Conceitos.

Assim sendo, dá-se um passo além de uma perspectiva puramente exegética da interpretação jurídica, na sua pretensão de pureza racional, objetividade e completude sistêmica - em comparação com as perspectivas que não admitem sequer a existência de lacunas jurídicas em razão do «princípio universal negativo», na afirmação de que se não há critério referente ao problema, isto significa que o direito não se pretende abarcá-lo. (CASTANHEIRA NEVES, 2013, p. 110).

Em seguida, importa enfrentar o «problema da axiologia» do direito, embora sem a possibilidade de esgotá-lo. Destaca-se que o nosso condutor não assume um radical intelectualismo ou emocionalismo em relação aos valores. (CABRAL DE MONCADA, 1966, p. 269). Logo, no processo de conhecimento dos valores, há sempre a relação entre a matéria, o dado (que é neste caso a vivência) e a forma (que é o conjunto de leis e categorias do pensamento que serve para organizar o dado). Logo, a partir da dinâmica entre estes elementos é que se possibilita o conhecimento axiológico. Nenhum sentimento valorativo poderá ser demonstrado por raciocínios prévios, mas necessariamente devem ser remetidos para o mínimo de intelectualização quando se pretende a alcançar a validade universal, com significado numa norma ou lei de aplicação. Conhecer, portanto, é o mesmo que organizar racionalmente as várias experiências axiológicas num sistema de valores que nos seja capaz de fornecer um critério adequado à realidade. Os valores em abstrato são produtos de uma consciencialização das múltiplas vivências valorativas, reduzindo-as à unidade de uma ideia e 
às coordenadas de um sistema, como é o caso da Ética. (CABRAL DE MONCADA, 1966, p. 269-273).

Nesse sentido, Moncada acredita que os valores jamais podem ser compreendidos em termos meramente lógicos-discursivos e nem através de uma abordagem puramente ideal. Há uma intuição imediata e pré-teorética da vida e da existência. Tal intuição é a primeira que nos diz que os valores são a própria vida do homem enquanto homem. É na existência humana, nas relações dinâmicas entre as consciências individuais e cultural-historicamente situadas que as esferas reais e ideias do Ser se interpenetram. Os valores, portanto, estão projetados para a realidade existencial, contudo, não podem deixar de provir de algo também real. De outro modo, se a totalidade dos valores não puder ser entendida independente de nós, pelo menos podem ganhar sentido em referência ao ser das coisas para o sentido último da realidade. (CABRAL DE MONCADA, 1966, p. 280-287).

Desta feita, conclui-se que o nosso filosofo do direito recusa as velhas acepções metafísicas das vertentes puramente racionalistas ou idealistas para assumir uma axiologia histórica e existencial.

A partir de algumas das considerações aqui expostas, Cabral de Moncada (1966, p. 288-289), na sua tentativa de compreensão do direito como dever-ser em todos os tempos e para além de todas as contingências, retorna ao problema do Direito Natural, na procura do sentido último da justiça.

\footnotetext{
"Trata-se nele de saber se para além de todas as opiniões e valorações contingentes que cada homem, cada povo, cada época representam e tantas vezes procuram impor aos outros, de facto alguma coisa haverá de justo e verdadeiro em si mesmo, com universal validade para todos os homens, todos os povos e todas as épocas; isto é, se para além do direito escrito que estes fizeram, haverá ainda lugar para aquele outro divino direito, que no dizer de Sófocles na Antigona, não é de hoje e não é de ontem, mas de todos os tempos e não foi inventado pelos homens [...]". (CABRAL DE MONCADA, 1966, p. 289).
}

Um primeiro passo para responder esta questão é distinguir dentro da própria ideia de direito o valor formal dos seus valores materiais (os conteúdos). $\mathrm{O}$ valor formal mais alto que se pode conceber é o da justiça. Isto se torna evidente pelo próprio fato de que a justiça é o resultado buscado pelas demais ideias já concebidas no conceito a priori de direito. Nestes termos, a ideia de justiça constitui algo de valioso por si mesmo, uma validade absoluta, universal e atemporal. Deste modo, por se tratar de um valor formal, pode ser colocada a 
serviço de qualquer conteúdo social, com o risco de ser instrumentalizada para os mais diversos fins sociais. (CABRAL DE MONCADA, 1966, p. 289).

Contudo, para prevenir este problema, sem abandonar ao aspecto formal dos valores, há ainda que conceber outro conhecimento que se impõe como validade absoluta e universal, ou seja, o reconhecimento da hierarquia dos valores, bem como a sua pressuposição como a condição primária para a realização da personalidade humana. A personalidade, portanto, é tida como condição e fonte de todos os valores, o que também vale para a necessidade de hierarquização dos mesmos. É possível dizer que é pela própria ideia de direito natural que se atribui o primeiro lugar na hierarquia aos valores espirituais (abstração dos valores históricos), que também impõe a considerar os valores vitais (tributários das situações da vida) como instrumentos para a realização dos primeiros. (CABRAL DE MONCADA, 1966, p. 290-291).

Entretanto, Moncada reconhece que tudo isto é insuficiente para edificar um direito natural útil para a prática. Contudo, sempre "se disse ser a justiça, em teoria, uma nobre ideia; a pessoa do homem, pelo menos em alguns aspectos, também uma nobre coisa; e as coisas do espírito, indiscutivelmente, superiores em dignidade às coisas materiais." (CABRAL DE MONCADA, 1966, p. 291). Nesse sentido, o jusfilósofo vai em defesa da existência de um «direito natural formal», que contém os elementos da justiça, da pessoa, do espírito e da vida em sua forma, como uma fé implícita que revela o seu conteúdo concretamente na realidade histórica, pois a razão humana não pode determinar a materialidade da justiça a priori de maneira absoluta e atemporal, como acreditava o jusracionalismo do séc. XVII e XVIII (CABRAL DE MONCADA, 1966, p. 291-292). Tratase, portanto, de um «direito natural de conteúdo variável». (CABRAL DE MONCADA, 1966, p. 292).

Tais coisas ditas, é necessário demarcar a relação entre a ética e o direito. Isto porque a ética e a moral, são, nesta perspectiva, as instâncias superiores que fornecem conteúdos para o direito, embora não possam ser identificados. Nem o direito pode perseguir indistintamente os fins da moral e nem a moral os fins do direito. É na moral e na ética que o direito busca o princípio da sua obrigatoriedade, caso queira ter o mínimo de validade e eficácia. A moral, desta feita, é a consciência mais exigente que o direito, contudo, os fins 
imediatos do direito são mais vinculados à prática para a vida em sociedade, como nos termos kantianos. (CABRAL DE MONCADA, 1966, p. 292-294).

É inegável reconhecer, portanto, que o pensamento de Cabral de Moncada ocupa o papel de verdadeira restauração das reflexões jurídico-filosóficas na Universidade de Coimbra no séc. XX, tendo em vista a recuperação dos problemas filosóficos aplicados ao direito; bem como da retomada da relação íntima e necessária entre direito e moral, na sua importância dada aos valores e ao problema do direito natural de conteúdo variável. Isto sem esquecer da referência prática no momento da interpretação e aplicação do direito, inclusive, na sua dimensão criativa, entre outras considerações já expostas. Logo, não é sem razão que este condutor abriu caminhos para uma vasta escola coimbrã em continuidade.

\section{CASTANHEIRA NEVES: A VOZ RENOVADORA E FUNDADORA DE UMA FILOSOFIA DO DIREITO.}

O pensamento jusfilosófico de António Castanheira Neves ${ }^{4}$ manifesta singularidade e relevância em escala global, dialogando com diversas construções teóricojurídicas ao redor do mundo sem submergir diante das mesmas. Trata-se de uma jusfilosofia atual, crítico-reflexiva, sistemática, metodológica e autêntica, orientada para pessoa humana em sua indisponibilidade axiológica, reconhecida através das relações de convivência que são verdadeiramente constitutivas da «validade do direito». (CASTANHEIRA NEVES, 2008b, p. 31-36).

Importa, deste modo, resgatar a exigência de um fundamento para as relações intersubjetivas, na afirmação de uma validade enquanto manifestação de um sentido normativo transindividual, através do qual os membros conviventes de uma comunidade se reconhecem como igualmente livres e responsáveis. (CASTANHEIRA NEVES, 2008b, p. 38). Nesse sentido, para a realização do direito orientada por essa unidade de sentido, põe-se em relevo a questão metodológica. A atividade judicativa é responsável em termos concretos pela realização do direito a partir de uma compreensão autônoma da sua materialidade, na medida em que não se deve recorrer a critérios externos ao direito, tendo em vista a finalidade de preservar a sua unidade de sentido integrante. (CASTANHEIRA NEVES, 2013, p. 234).

\footnotetext{
${ }^{4}$ António Castanheira Neves é licenciado e doutorado (1967) pela Faculdade de Direito da Universidade de Coimbra, onde atual como professor catedrático até a sua jubilação em 1999. Foi regente das cadeiras de Introdução ao Estudo do Direito, Filosofia e Metodologia do Direito, bem como lecionou também Metodologia do Direito na Universidade Católica Portuguesa. (SOUSA, 2005, p. 219).
} 
Infelizmente não será possível percorrer por todas as dimensões da sua vasta obra. Devemo-nos concentrar nas críticas e propostas mais diretas de superação do que se entende, lato sensu, por positivismo jurídico, em suas perspectivas formalistas, legalistas e pretensões científico-descritivas. Contudo, antes se faz necessário compreender o seu ponto de partida. Trata-se, portanto, de uma construção voltada para solução da crise atual da filosofia do direito.

Não há de se estranhar a situação de crise do direito, pois este não está imune à crise generalizada no mundo da vida que é a nossa circunstância presente. Os valores agora já não orientam mais o projeto humano, mas sim outras intenções ordenadoras. $\mathrm{O}$ dogmatismo vai em defesa apenas da sua própria segurança, evidenciando favorecer um certo grupo específico. Vê-se, portanto, um real sacrifício da ética, senão a sua própria negação, em nome de uma objetividade normativa e a da funcionalização do direito. Esta objetivação, fundada em termos impessoais e formalistas, apaga a subjetividade na sua real situação histórica (CASTANHEIRA NEVES, 2011b, p. 27-28).

Neste mesmo sentido, há também problemas decorrentes das perspectivas sociológicas que, ao encararem o direito como parte de uma estrutura social, procuram dar resposta às questões não-jurídicas através do direito, no intuito de promover mudanças radicais estruturais. Esta estratégia também combina fatores ideológico-políticos e econômicos que repercutem no fenômeno da estatização do direito, voltada para renunciar a autonomia do jurídico diante do político e, por conseguinte, para reduzir o direito à técnica, na disponibilidade do legislador para realização de seus fins. (CASTANHEIRA NEVES, 2011b, p. 28).

Trata-se de converter o Direito numa «ordem da necessidade», ou seja, de conceber uma alternativa de direito que o substitui pelo poder, em oposição à validade axiológica, não só porque o encara como uma estrutura de dominação, mas porque invoca um discurso de necessidade de um qualquer "absoluto ideológico" num quadro estratégico de forças que se põem a vencer as resistências políticas e, por isso, tende a suprimir a autonomia e as diferenças que não se encaixam nessa dinâmica, senão a própria dignidade. Não obstante, em um Estado Democrático, há a possibilidade de se colonizar por uma «ordem da finalidade», no seu objetivo de realizar de certos fins político-sociais contingentes, ratificados ou determinados pela vontade de uma autoridade, resultando na substituição da validade 
axiológica por um finalismo social que orienta a decisão judicativa pelos efeitos socialmente verificáveis (CASTANHEIRA NEVES, 2011, p. 300-307). Esta subordinação do jurídico ao político vem pré-anunciada desde o período pós-revolucionário do séc. XVII e XVIII, que identificou o direito à lei. Tal acepção abriu margem para torná-lo instrumento técnico à serviço do plano político, que não teria sido possível se não tivesse por fundamento a posição ontológico-cultural do positivismo. (CASTANHEIRA NEVES, 2011b, p. 29).

Desta feita, o positivismo científico sob influência de Comte, enquanto movimento de superação da metafísica, não se restringe ao repúdio do jusnaturalismo racionalista no seu dogmatismo acrítico, sistemático e ahistórico. Ele rejeita também a intenção axiológica-normativa do direito, desvirtuando assim os problemas fundamentais de validade, para identificar o direito com um mero "dado" exterior e indiferente às relações humanas, passível de ser apreendido num processo de conhecimento empírico. Dá-se aqui uma construção puramente científica do direito enquanto objeto de apreensão teorética, que culmina para a elaboração de uma "Ciência do Direito". "O pensamento jurídico deixou de se preocupar com a validade e a intencionalidade normativas do direito [...] para curar apenas da validade e intencionalidade cognitivas de um pensamento sobre o direito" (CASTANHEIRA NEVES, 2011b, p. 30).

Nesse sentido, o cognitivismo jurídico, que também é um dos responsáveis por desenvolver uma abordagem normativista, recai no erro de reduzir o direito à estrita objetividade e à autossubsistência. Tal objetividade o situa numa exterioridade cognitiva, como se o direito pudesse se constituir externamente às relações humanas. Logo, isto equivale a dizer que o pensamento jurídico não contribui em nada para a sua constituição, na medida em que o direito já existe, basta apenas identificá-lo cientificamente. O direito seria então apreendido tal "como ele é" (CASTANHEIRA NEVES, 1998, p. 60-61), sem necessária convergência para um dever-ser. Tal indiferença axiológico-normativa, em nome da neutralidade e objetividade científica, recai numa ausência de autonomia crítica de constituição-realização do direito, pois, na medida em que o compreendemos apenas como objeto, o mesmo não só está pronto para aceitar qualquer conteúdo desde que imposto, sem uma necessária referência material axiológica-normativa, como também está vulnerável diante de qualquer articulação déspota e tirana. (CASTANHEIRA NEVES, 2011b, p. 30).

Além do mais, a perspectiva estritamente normativista acaba por pré-determinar e restringir o campo objetivado e os tipos de experiências problemáticas que direito já 
reconhece, não sendo capaz de assimilar novos problemas, passando estes a se tornarem, na verdade, respostas já disponíveis. Isto é incompatível com a própria dimensão histórica da experiência problemática, que se expande constantemente formulando novas perguntas (novos problemas) e, por conseguinte, buscando novas respostas, que assumem novas intencionalidades através dos novos problemas. Isto nos impõe concluir, que o direito requerido pelo caso concreto é sempre mais do que aquele objetivado num sistema de normas e, por esta razão, o sistema não pode se identificar como o todo do direito, haja vista que a prática social é historicamente constiuenda de novos problemas e novos valores, o requer uma perspectiva histórica e aberta de realização. (CASTANHEIRA NEVES, 1998, p. 61-63).

Trata-se de romper radicalmente com uma perspectiva epistemológica do positivismo sociológico, voltada apenas a observar e descrever a realidade do direito como um objeto, haja vista que as relações prático-sociais é que constituem o direito. Neste sentido, não se pode referir ao direito como um objeto meramente externo, apreendido pela vontade de uma autoridade, mas importa assumir o direito por dentro, no seu verdadeiro modo de ser de intencionalidade normativamente constitutiva em face da problematicidade (CASTANHEIRA NEVES, 1998, p. 62).

Nesse sentido, a perspectiva Jurisprudencialista de Castanheira Neves diverge radicalmente de um "platonismo de regras", no qual há a mera aplicação a posteriori de um critério previamente estabelecido sem qualquer significação normativa diante do problema (CASTANHEIRA NEVES, 1998, p. 63). O verdadeiro problema metodológico do direito, para Castanheira Neves, não está na dedução a partir de premissas gerais e abstratas, mas na elaboração de tais premissas como critérios para o problema-caso, haja vista que tanto a seleção da norma aplicável, como a formulação das premissas só são possíveis a partir de um juízo previamente autônomo do julgador, que orientavam totalmente a subsunção. (CASTANHEIRA NEVES, 2011d, p. 258-259).

A nossa voz condutora adverte que a realização do direito é o verdadeiro momento nuclear da constitutiva normatividade. O direito deve deixar de ter o prius na norma para passar a ter o seu prius metodológico no problema/caso concreto, na medida em que o direito é verdadeiramente realizado através da resolução do caso pelo juízo decisório. Há aqui uma real necessidade de invocar fundamentos normativos extratextuais, sejam eles interesses, fins ou valores assumidos pelo direito no momento da sua realização, em referência à 
problematicidade concreta, para também considerar o juízo decisório como constitutivo do direito. (CASTANHEIRA NEVES, 1998, p. 63-64). Tal dimensão criativa da prática decisória existe para além da integração de lacunas, uma vez que é inerente ao juízo, corroborando para o desenvolvimento autônomo do direito. (CASTANHEIRA NEVES, 1998, p. 64).

Assim sendo, sobre o dualismo metódico interpretação/aplicação, na esteira de Radbruch, a interpretação não é mera explicitação do conteúdo do texto, mas sim constitutiva atribuição de um sentido jurídico ao conteúdo, em função de uma referência normativa sempre vinculada ao caso concreto (CASTANHEIRA NEVES, 2011c, p. 259). Trata-se de uma clara superação da visão de que o texto da lei é o único objeto da interpretação e de que o mesmo carrega um significado puramente hermenêutico, recusando um lugar dentro teoria subjetivista (que recorre à vontade do legislador); na teoria objetivista (que intenta extrair o significado do texto por si mesmo); assim como uma abordagem puramente teleológica. Todas estas modalidades, ao recaírem em extremismos, ora relegam a dimensão histórica, axiológica, prática-problemática ou sistemática de realização do direito (CASTANHEIRA NEVES, 2011d, p. 354-362).

O objeto da interpretação, portanto, não pode se restringir ao texto da lei, como nos termos do positivismo legalista, na medida em que a normatividade não é encontrada a partir de uma pura tarefa hermenêutica. O que importa extrair é a norma que este texto guarda e que pretende realizar diante do problema in concreto. A norma é sempre um resultado a atingir mediante um texto. (CASTANHEIRA NEVES, 2011d, p. 341).

Desta feita, há de se verificar uma unidade normativo-metodológica entre interpretação e aplicação. A interpretação não é realizada a priori, cristalizada em uma norma antecipada em abstrato antes de sua referência ao caso, mas sim constituída na sua relação hermenêutico-normativa. Esta relação integra a própria realidade social que o caso manifesta no processo de realização do direito, bem como revela assim um momento constitutivo da normatividade jurídica. Deste modo, a interpretação se consuma apenas na decisão concreta. (CASTANHEIRA NEVES, 1998, p. 65-66). Isto implica concluir que no momento de interpretação-realização do direito, a norma vê-se duplamente transcendida, pois, além de se constituir apenas através do caso, também realiza a intencionalidade fundamentante dos princípios, que são determinantes para o sentido do direito e, igualmente, para realização do direito na prática. (CASTANHEIRA NEVES, 1998, p. 66). 
Ainda, é importante alertar que a proposta Jurisprudencialista de Castanheira Neves não recorre ao Direito Natural ou para a assimilação pura da moralidade contingente como via de superação do positivismo jurídico. Trata-se, na realidade, de conceber uma separação entre o direito e a moral no âmbito do não-positivismo, na medida em que a validade jurídica é reconstituída a partir de uma normatividade interna ao direito, que convoca uma racionalidade prática sujeito/sujeito, numa historicidade constitutiva, e não simplesmente sujeito-objeto. Desta feita, vai-se em defesa de um conteúdo material autônomo da juridicidade, constituendo através de uma experiência de circularidade prática das relações comunitárias intersubjetivas, seja entre officials e não-officials, numa ordem de validade comunitária na qual se estabelece um vínculo axiológico trans-subjetivo, que projeta culturalmente uma intenção de validade (AROSO LINHARES, 2016, p. 434).

Nesse sentido, importa clarificar que apesar de Castanheira Neves assimilar a experiência de realização e constituição do direito como autônoma, o jusfilósofo não assume que esta seja alheia à realidade, na medida em que leva em consideração os valores e outras circunstâncias histórico-comunitárias, que são reconstituídas internamente na ordem jurídica em sua unidade integrante de sentido. Por esta razão, importa dizer que a proposta jurisprudencialista encara o Direito enquanto alternativa propriamente humana. Uma alternativa possível para um problema necessário da convivência, pois apesar da irrecusável condição mundanal e antropológico-existencial, a única condição indispensável para que se constitua o direito enquanto tal é a «condição ética», que presume uma ordem comunitária de pessoas que se reconhecem e se respeitam reciprocamente, e que pretendem realizar normativamente o que assumem como validade, ou seja, o «direito é a ordem de validade». (CASTANHEIRA NEVES, 2011, p. 297-298).

\section{CONCLUSÃO}

Apesar das inevitáveis omissões, considera-se que o presente estudo engradece todo o mundo lusófono-jurídico que é abrigado pela Faculdade de Direito da Universidade de Coimbra há muitos séculos e que contínua a exercer considerável influência contemporânea. Não é sem razão que os nossos condutores, todos grandes nomes da Faculdade de Direito da Universidade de Coimbra dos últimos cem anos, não deixaram de manifestar o seu pensamento crítico, haja vista o intuito de preservar as reflexões jusfilosóficas, na sua 
exigência por uma orientação axiológica e crítica da prática, numa clara afronta contra à mentalidade puramente cognitiva e impositiva do positivismo jurídico.

Desta feita, a nossa primeira voz condutora, Paulo Mêrea, apesar de sua aparente vulnerabilidade na posição de estudante, elaborou um discurso paradigmático e que sempre será lembrado como uma manifestação insurgente contra as tendências mitigadoras dos direitos subjetivos do início do século XX, na sua abordagem pluralista no esgotar dos limites do pensamento moderno, desde já nos alertando que receberia o reconhecimento merecido de «Sábio».

Já a nossa segunda voz, Cabral de Moncada, foi responsável por retomar a Filosofia do Direito, em detrimento do puro sociologismo e das suas pretensões de neutralidade cognitiva, dando abertura para uma grandiosa escola de pensadores jusfilósofos. Logo, apesar de não ter constituído um pensamento com estruturas de inteligibilidade propriamente jurídicas, sempre será lembrado como o responsável por retomar as reflexões críticas e normativas sobre o direito na FDUC.

Por fim, a nossa última voz condutora, Castanheira Neves, não só tem um papel de extrema relevância na história ora descrita, como possui um inegável prestígio no pensamento jurídico contemporâneo, uma vez que oferece uma solução original para o problema do direito hoje, pensada em termos propriamente jurídicos, e que não deixa de travar um claro embate com demais jusfilósofos de todo o mundo. Por tais razões, é com grande gosto que os estudantes de Coimbra difundem tal pensamento. Trata-se, portanto, de uma proposta que não pretende resgatar o direito natural, ainda que formal (como propõe o nosso segundo condutor), assim como está longe de identificar o direito aos conteúdos puramente morais contingentes, na medida em que os reconstitui internamente ao direito para a preservação de uma autônoma validade normativa comunitária e da própria condição de pessoa em sua inviolável dignidade.

\section{REFERÊNCIAS}

AROSO LINHARES, José Manuel. In defense of a non-positivist separation thesis between law and morality. In: RphZ Rechtsphilosophie Zeitschriftfür Grundlagen des Rechts. Verlag C.H.BECK, 2016, p. 425-443.

CABRAL DE MONCADA, Luís. O ensino da filosofia do direito. In: Boletim da Faculdade de Direito da Universidade de Coimbra. Vol. 14, Coimbra: Universidade de Coimbra, 1937-1938, p. 163-167. 
CABRAL DE MONCADA, Luís. Para a história da filosofia em Portugal no séc. XX. In: Boletim da Faculdade de Direito da Universidade de Coimbra. Vol. 36. [s.n]. Coimbra: Coimbra Editora. 1960. p. 1-15.

CABRAL DE MONDOCADA, Luís. Filosofia do Direito e do Estado vol. II: Doutrina e Crítica. Coimbra: Atlântida Editora, 1966

CABRAL DE MONCADA, Luís. Sobre a Epistemologia Jurídica. In: Estudos de Filosofia do Direito e do Estado. Vol II. Lisboa: Imprensa Nacional-Casa da Moeda, 2004.

CABRAL DE MONCADA, Luís. Subsídios para uma história do Direito em Portugal. Lisboa: Imprensa Nacional-Casa da Moeda, 2003.

CASTANHEIRA NEVES, António. Teoria do Direito: Lições proferidas no ano lectivo de 1999 e 1998. Coimbra: Universidade de Coimbra, 1998.

CASTANHEIRA NEVES, António. O Direito como alternativa humana. Notas de reflexão sobre o problema actual do direito. In: Digesta: Escritos acerca do direito, do pensamento jurídico, da sua metodologia e outros. Vol. 1, Reimpressão Coimbra: Coimbra Editora, 2011, p. 287-310.

CASTANHEIRA NEVES, António. O papel do jurista no nosso tempo. In: Digesta: Escritos acerca do direito, do pensamento jurídico, da sua metodologia e outros. Vol. 1, Reimpressão Coimbra: Coimbra Editora, 2011b, p. 9-50.

CASTANHEIRA NEVES, António. O Actual Problema Metodológico de Realização do Direito -1. In: Digesta: escritos acerca do direito, do pensamento jurídico, da sua metodologia e outros. Volume 2. Reimpressão. Coimbra: Wolters Kluwer/Coimbra Editora, 2011c, p. 249-282.

CASTANHEIRA NEVES. Interpretação Jurídica - 3. In: Digesta: escritos acerca do direito, do pensamento jurídico, da sua metodologia e outros. Volume 2. Reimpressão. Coimbra: Wolters Kluwer/Coimbra Editora, 2011d, p. 337-377

CASTANHEIRA NEVES, António. Apresentação de Filosofia do Direito e do Estado de Luís Cabral de Moncada. In: Digesta: Escritos acerca do direito, do pensamento jurídico, da sua metodologia e outros. Vol. 3, Coimbra: Coimbra Editora, 2008, p. 529-544

CASTANHEIRA NEVES, Antônio. Coordenadas de uma reflexão sobre o problema universal do direito - ou as condições de emergência do direito como direito. In: Digesta: Escritos acerca do direito, do pensamento jurídico, da sua metodologia e outros. Vol. 3. Coimbra: Coimbra Editora, 2008b, pp. 9-48

CASTANHEIRA NEVES, Antônio. Metodologia Jurídica. Problemas Fundamentais. STVDIA IVRIDICA. Reimpressão. Coimbra: Coimbra Editora, 2013 
MARCOS, Rui Manuel de Figueiredo. O sábio Paulo Merêa. In: Boletim da Faculdade de Direito da Universidade de Coimbra. Vol 90, t. 1, 2014, p. 449-459

PAULO MÊREA, Manuel. Idealismo e Direito. In: Boletim da Faculdade de Direito da Universidade de Coimbra. Vol. 49. Coimbra: Universidade de Coimbra, 1973, p. 285-324

REIS MAQUES, Mario; GAUDÊNCIO, Ana Margarida Simões; LINHARES, José Manuel Aroso. Os cem anos do boletim na sua vertente jurídico-filosófica. In: Boletim de Faculdade de Direito da Universidade de Coimbra. Vol. 91. Coimbra: [s.n], 2015, p. 3-149.

SOUSA, Ana Paula Loureiro de. $\mathbf{O}$ pensamento filosófico-jurídico português contemporâneo. Lisboa: Imprensa Nacional-Casa da Moeda, 2005.

TEIXEIRA, António Braz, “Apresentação”. In: CABRAL DE MONCADA, Luís. Subsídios para a História da Filosofia do direito em Portugal. Lisboa: Imprensa Nacional-Casa da Moeda, 2004.

TEIXEIRA, António Braz. O pensamento filosófico-jurídico português. $1^{\text {a }}$ edição. Vol. 85. Lisboa: Instituto de Cultura e Língua Portuguesa, 1983. 